Journal of Physical Education and Sport Studies

Beden Eğitimi ve Spor Araştırmaları Dergisi

e-ISSN 2602-3644

\title{
The Effect of 14 Weeks Volleyball Course on Physical Education Teacher Education Students' Content Knowledge
}

\section{Haftalık Voleybol Dersinin Beden Eğitimi Öğretmen Adaylarının Alan Bilgisine Etkisi}

\section{Erhan DEVRILMEZ ${ }^{1}$ iDhttps://orcid.org/0000-0002-5136-7510}

School of Physical Education and Sport, Karamanoglu Mehmetbey University, Karaman, Turkey

\section{Mustafa ÇABITÇI IDhttps://orcid.org/0000-0003-3601-9048}

Institute of Social Science, Karamanoglu Mehmetbey University, Karaman, Turke

\section{Halil İbrahim UYAR iDhttps://orcid.org/0000-0001-7975-9893}

Institute of Social Science, Karamanoglu Mehmetbey University, Karaman, Turkey

\section{Dilem çiY (iD https://orcid.org/0000-0001-6283-4033}

Institute of Social Science, Karamanoglu Mehmetbey University, Karaman, Turkey

Kevser BOZKURT (iD https://orcid.org/0000-0002-8024-953X

Institute of Social Science, Karamanoglu Mehmetbey University, Karaman, Turkey

\section{Fatih DERVENT ID https://orcid.org/0000-0002-2612-3549}

Faculty of Sport Sciences, Marmara University, Istanbul, Turkey 
Abstract

Volleyball course takes place on secondary and high school curriculums. It also takes place on physical education teacher education undergraduate programs. Physical education teacher education students are supposed to have volleyball content knowledge before graduating teacher education programs. This study aims to examine physical education teacher education students' volleyball content knowledge level after they newly completed volleyball course. Participants were 15 female and 23 male, totally 38 students. Data were collected with volleyball common content knowledge test and content map. Paired sample t-test and descriptive statistics were utilized for statistical calculations. Results showed that while participants reached expected common content knowledge level $70 \%$ and over), their specialized content knowledge levels were lower than expected (3.0 or over). As a conclusion, common content knowledge focused course increased physical education teacher education students' common content knowledge level. Specialized content knowledge which directly affects physical education teacher education students' quality can be obtained by content and applications focusing on it.

Key Words: Content knowledge, Volleyball, Physical education teacher education

\section{Öz}

Voleybol, ortaokul ve lise beden eğitimi ve spor dersi ögretim programının yanı sıra beden eğitimi öğretmeni yetiştiren kurumların lisans programlarında da yer almaktadır. Beden eğitimi öğretmen adaylarının öğretmen yetiştiren kurumlardan mezun olmadan önce yeterli voleybol alan bilgisine sahip olmaları gerekmektedir. Bu çalışmanın amacı, voleybol dersini yeni tamamlamış beden eğitimi ve spor öğretmenliği bölümü öğrencilerinin voleybol alan bilgisi düzeyinin incelenmesidir. Çalışmaya 15 kadın ve 23 erkek, toplam 38 beden eğitimi ve spor öğretmen adayı katılmışıı. Veri toplama aracı olarak voleybol genel alan bilgisi testi ve içerik haritası kullanılmıştır. Toplanan veriler bağımlı örneklem t-testi ve tanımlayıı istatistik kullanılarak analiz edilmiştir. Bulgulara göre katılımcıların genel alan bilgisi istendik düzeye ulaşırken (\% 75 ve üzeri), özelleşmiş alan bilgisi değerleri beklenen düzeyin (3.0 ve üzeri) oldukça altında bulunmuştur. Sonuç olarak, genel alan bilgisi odaklı bir ders sonrası öğretmen adaylarının genel alan bilgisi düzeyleri de anlamlı olarak artmıştır. Beden eğitimi öğretmen adaylarının öğretim kalitesini doğrudan etkileyen özelleşmiş alan bilgisi de ancak ona odaklanan içerik ve uygulamalarla kazandırilabilir.

Anahtar Kelimeler: Alan bilgisi, Voleybol, Beden eğitimi öğretmen eğitimi

\section{Giriş}

Voleybol, sınırlı alanda ve düşük maliyetli malzeme ile oynanabilen popüler takım sporlarından biridir (Aslan, 1979; Yerlisu \& Çelenk, 2008). Türkiye'de ortaokul ve lise beden eğitimi ve spor dersi öğretim programının yanı sıra beden eğitimi öğretmeni yetiştiren kurumların lisans programlarında da yer almaktadır. Voleybolun popülerliğinin nedenleri arasında lisanslı sporcu ve hakem sayısı en çok olan spor dalı olması (Spor Genel Müdürlüğü, 2018) ve materyal açısından okul beden eğitimi derslerinde öğretiminin kolaylığı gösterilebilir. Türkiye'de beden eğitimi ve spor öğretmenliği bölümlerinin dersleri, yakın zamanda güncellenen Yükseköğretim Kurumu beden eğitimi ve spor öğretmenliği lisans programına bağlı olarak yürütülmektedir (YÖK, 2018). Voleybolun önceki lisans programında zorunlu ders olarak öğretilmesi gerekirken, yeni müfredatta seçmeli takım sporları içinde yer almaktadır. Voleybol branşının yaygınlığı ve okullarda öğretilmeye uygun olması nedeniyle, beden eğitimi öğretmen adaylarının öğretmen yetiştiren kurumlardan mezun olmadan önce yeterli voleybol alan bilgisine sahip olmaları gerekmektedir. 
Bir beden eğitimi öğretmeninin voleybolda bir beceriyi ya da bir başka öğretmenin farklı bir konuyu öğretebilmek için intiyaç duyduğu bilgi alan bilgisi olarak adlandırımaktadır (Grossman, 1990; Shulman, 1986). Çalışmalara göre alan bilgisi öğretmenler ve öğretmen adayları için gerekli bilgilerin başında gelmektedir (Hastie \& Vlaisavljevic, 1999; Siedentop, 2002). Alan bilgisi, matematik (Ball, Thames, \& Phelps, 2008) ve beden eğitimi (Ward, 2009) alanlarında genel alan bilgisi (GAB) ve özelleşmiş alan bilgisi (ÖAB) olarak ikiye ayrılmaktadır. GAB bir öğretmenin ne öğreteceğini bilmesi; ÖAB ise nasıl öğretileceğini bilmektedir.

Çalışmalar ÖAB gelişstirilen beden eğitimi öğretmenlerinin ve beden eğitimi öğretmen adaylarının pedagojik alan bilgilerinin (PAB) de geliştiğini göstermektedir (Iserbyt, Ward, \& Martens, 2015; Kim, Ward, Sinelnikov, Ko, Iserbyt, Li, \& Curtner-Smith, 2018; Sinelnikov, Kim, Ward, Curtner-Smith, \& Li, 2016; Ward, Kim, Ko, \& Li, 2015). PAB, öğretmenin belirli bir konu alanını öğrencilerine aktarırken kullandığı kolaylaştırıcı öğretim tasarımları planlaması ve kullanması olarak açıklanmaktadır (Shulman, 1986; 1987). PAB öğrencilerin öğrenme düzeyinin istenen seviyeye ulaştırılması için bir öğretmenin sahip olması gereken bilgidir ve etkili öğretim için vazgeçilmezdir (Shulman, 1986; 1987; Ward \& Ayvazo, 2016). Kavramsal açıdan karıştırılan ÖAB ve PAB arasındaki fark bir örnekle açıklanabilir. Bir beden eğitimi öğretmeninin hentbolda temel pasın öğretim basamaklamasını basitten karmaşığa küçük adımlarla başlangıcından bitişine kadar bilmesi, o öğretmenin ÖAB olarak açıklanır. Aynı öğretmen temel pası 7. sınıflara öğretirken kullandığı öğretim tasarımlarını, 11. sınıflara uygularken çeşitli uyarlamalar ve uygulamalarla farklılaştırabiliyor olması, o öğretmenin PAB olarak tanımlanır. Yeterli ve derin ÖAB'ne sahip olmak bu nedenle önemlidir.

Beden eğitimi öğretmenleri okul beden eğitimi derslerinde fiziksel aktivite ve spor derslerini öğretebilmesi için yeterli alan bilgisine sahip olmaları gerekmektedir. Yeterli alan bilgisine sahip olmadan fiziksel aktivite ve spor dersini öğreten öğretmen, çoğunlukla aynı becerileri ya da teknikleri tekrar etmekte dolayısıyla öğrencilerin öğrenme düzeyi düşük kalmaktadır (Siedentop, 2002). Yeterli alan bilgisine sahip olmak için GAB ve ÖAB alt boyutlarının ikisinin de yeterli olması beklenmektedir.

Beden eğitimi öğretmenlerinin fiziksel aktivite ve spor derslerindeki alan bilgisini üniversitelerin beden eğitimi öğretmen yetiştiren kurumlarda elde ettikleri düşünüldüguünde, beden eğitimi öğretmen yetiştiren kurumlardaki derslerin önemi ortaya çıkmaktadır (Ward vd., 2015). Bu çalışmanın amacı, voleybol dersini yeni tamamlamış beden eğitimi ve spor öğretmenliği bölümü öğrencilerinin voleybol alan bilgisi düzeyinin incelenmesidir.

\section{Yöntem}

Çalışma için araştırmanın yapııdığı devlet üniversitesinden etik kurul onayı alınmıştır. Ayrıca katıımcılar bireysel olarak gönüllü katıım belgesini imzalamıştır.

\section{Araştırmanın Katılımcıları}

Çalışmaya Türkiye'deki bir devlet üniversitesinde öğrenim gören 44 beden eğitimi ve spor öğretmenliği bölümü öğrencisi katılmıştır. Katılımcılar 3. sınıf öğrencisidir ve voleybol dersini zorunlu takım sporları dersi olarak takip etmişlerdir. Devamsızlık, sakatlık, kayıt sildirme gibi nedenlerle 6 öğrenci dersi tamamlayamamış ve çalışma 38 öğrencinin katılımı ile gerçekleşmiştir. Katılımcılar 15 kadın ( $X^{-}$yaş= 21.58, SS=1. 65) ve 23 erkek ( $X^{-}$yaş= 23.71, SS= 2.33) öğrenciden oluşmaktadır. Katılımcıların geçmiş voleybol bilgileri sorulduğunda, 14 öğrencinin önceden lisanslı olarak voleybol oynadığı ve 6 öğrencinin lisanslı olarak olmasa da okul takımlarında voleybol sporu ile ilgilendiği belirlenmiştir. 


\section{Araştırma Tasarımı}

Bu çalışmada tek grup ön ve son test deneysel tasarımı kullanılmıştır. Bu tasarım deneysel tasarımlar arasında zayıf olarak kabul edilmesine rağmen kontrol grubunun varlığının söz konusu olmadığı ve neden-sonuç ilişkisinin test edildiği durumlarda kullanılması önerilmektedir (Creswell, 2012). Çalışma grubumuzdan dönemin ilk dersinin başında ön test verileri toplanmış, katılımcılar 14 haftalık voleybol dersini tamamlamış ve dersin sonunda katılımcılardan son test verileri toplanmıştır.

\section{Ders Öğretim Elemanı}

Voleybol dersini öğreten öğretim elemanı 52 yaşında ve yüksek lisans mezunudur. Beden eğitimi ve spor öğretmenliği bölümünde yaklaşık 20 yıldır voleybol derslerini vermektedir. Ayrıca voleybol üzerine iki adet kitabı bulunmaktadır. Dersin öğretim elemanından dersi takip etme, veri toplama ve ders müfredatını temin etme konularında izin alınmıştır.

\section{Veri Toplama Süreci}

\section{Genel Alan Bilgisi}

Katılımcıların GAB düzeyini belirlemek için Devrilmez, Dervent ve Yoruç Çotuk (2019) tarafında geliştirilen 20 soruluk voleybol GAB testi kullanılmıştır. Test çoktan seçmeli 7 kural, 8 teknik ve 5 taktik sorusundan oluşmaktadır. Tek bir doğru cevabın olduğu soruların uyum indeksi yüksek bulunmuştur. Katılımcıların testten başarıı olabilmeleri için toplam soruların en az \%70'ini doğru olarak cevaplamaları gerekmektedir (Castelli \& Williams, 2007).

\section{Özelleşmiş Alan Bilgisi}

\section{Içerik Haritası}

Öğrencilerin ÖAB düzeyini test etmek için Ward ve arkadaşları (2017) tarafından geçerliği ve güvenirliği sağlanan içerik haritası kullanılmıştır. Iç̧erik haritası boş bir kâğıt üzerine öğretilmek istenen beceri/tekniklerin derslerde kullanılması planlanan basamaklamaları içerir. Katıımcılar, içerik haritasını aldıklarında voleybol ile ilgili öğretmeyi planladıkları teknikleri boş kâğıdın en altına soldan sağa olacak şekilde yazar. Sonrasında her teknik için yukarı doğru öğretimde kullanmayı planladığı basamakları belirtir. Son olarak da öğretim sırasında birbirleriyle ilişkili olduğunu düşündüğü ve öğretim de kullanmayı planladığı teknikleri birbiriyle eşleştirir. İçerik haritalarında tek bir doğru yoktur ve istenildiği sayı da teknik ve eşleştirme yazılabilir. Tamamlanan içerik haritaları dolduran katılımcının ÖAB düzeyini gösterir (Ward vd., 2017).

\section{Öğretim Tasarımı Geliştirme Kategorileri}

İçerik haritalarında yer alan öğretim tasarımları, katıımcının ÖAB düzeyini belirlemekte kullanılır (Ward vd., 2017). Öğretim tasarımı geliştirme kategorileri yedi kategoriden oluşmaktadır (Ward vd., 2017); 1) Bilgilendirme (Bi): Dersin başlangıcında kullanılan ilk teknik ya da beceri. 2) Basamaklama (BA): Derste öğretilen beceri ya da tekniğin zorluk derecesinin arttırıması ya da azaltılması. 3) ìileştirme (iY): Derste kullanılan beceri ya da tekniğin uygulama kalitesinin arttırıması. 4) Maç/oyun uygulaması (MU): Maç ya da oyun performansının uygulanması. 5) Uygulamada değerlendirme (UD): Maç ya da oyun olmaksızın kişinin kendi ya da arkadaşının performansını değerlendirmesi. 6) Uygulamada basamaklama (UB): Oyun ya da maç performansı sırasında uygulanan öğretim tasarımının zorlaştırılması ya da kolaylaştırılması. 7) Uygulamada iyileştirme (Ui) : Maç/oyun sırasında öğretim 
tasarımlarının performans kalitesinin arttıııması. Belirtilen kategoriler içerik haritalarındaki öğretim tasarımı geliş̧irme kategorilerinin kodlanmasında ve ÖAB düzeyini belirlemek için kullanılan formülde yer almaktadırlar.

\section{Öğretim Tasarımı Geliştirme Formülü}

Katılımcıların öğretim tasarımı geliştirme derinliği, alan yazındaki çalışmaların (Dervent, Devrilmez, Ince, \& Ward, 2018; Tsuda, Devrilmez, Dervent, \& Ward, 2017; Ward vd., 2017) geçerli ve güvenilir olduğunu gösterdiği formülü ile hesaplanmaktadır. Formülde bilgilendirme kategorisi paydada yer alırken, diğer kategoriler payda yer almaktadır. Formüle göre içerik haritasını dolduran kişi bilgilendirme kategorisi dışında ne kadar çok diğer kategorileri kullanırsa, öğretim tasarımı geliştirme derinliği o kadar fazla olmaktadır. Çalışmamızda yer alan katıımcıların ÖAB düzeylerinin yeterli kabul edilebilmesi için yukarıda belirtilen formülden 3.0 ve üzeri skora sahip olunması kriter olarak belirlenmiştir. Yapılan çalışmalar belirlenen kriterin ÖAB düzeyinin tespit edilmesinde ve güçlü ve zayıf ÖAB'nin belirlenmesinde kullanılabilir olduğunu göstermiş̧ir (Dervent vd., 2018; Ward, Tsuda, Dervent, \& Devrilmez, 2018).

\section{Kodlayıcılar Eğitimi ve Gözlemci Tutarııı̆ı}

Toplanan verilerin kodlanmasında üç kodlayıcıdan destek alınmıştır. Kodlayıcılar Dervent, Tsuda, Devrilmez ve Ward (2016) tarafından belirtilen üç aşamalı eğitim prosedürünü takip etmişlerdir. Aşamalardan birinde başarısız olduklarında tekrar başa dönmüş ve prosedürü tamamlayana kadar eğitime devam etmişlerdir. Kodlayıcılar arası tutarlıı̆ı test etmek için toplam içerik haritalarının \%33'ü $(\mathrm{N}=38 / 3=13)$ kodlayıcılar tarafından kodlanmış ve tutarlılık .96 olarak tespit edilmiştir. Belirlenen tutarlılık değeri yüksek bulunmuş̧tur (Van der Mars, 1989).

\section{Voleybol Ders Müfredatı}

Çalışmamızda yer alan voleybol dersinin ders müfredatının uygunluğu test edilmişsir. Toplam 14 hafta devam eden dersin \% 80'i bu çalışmanın ilk yazarı tarafından takip edilmiştir. ilk değerlendirme, müfredat ve uygulamaların kontrolü ile ilgilidir. Ders müfredatı dersin öğretim elemanından temin edilmiş ve hafta hafta müfredat ile ders uygulamaları arasındaki tutarlılık kontrol edilmiştir. Öğretim elemanının ders müfredatında yer alan konuları gerçek ders uygulamalarına tutarlı şekilde aktardığı tespit edilmiştir. Ikinci değerlendirme, ders müfredatında alan bilgisinin hangi alt boyutuna (GAB ya da ÖAB) vurgu yapıldığı ve bu alt boyutun uygulamalara yansımasının kontrol edilmesidir. Ders müfredatının GAB odaklı olduğunu görülmüştür. Öğretim elemanı ile yapılan görüşmeler ve ders uygulamaları, voleybol dersinin GAB odakı işlendiğini ve tamamlandığını göstermektedir.

\section{Verilerin Analizi}

Verilerin analizinden önce varsayımlar kontrol edilmiştir. Grupların normal dağılım sağladıkları basıklık-çarpıklık değerleri ve p-p plotlar ile kontrol edilmiş ve normal dağılım sağladıkları tespit edilmiştir. Varsayımlara göre bu çalışmada parametrik testlerden ve bağımlı örneklem t-testi ve tanımlayıcı istatistik kullanılmıştır.

\section{Bulgular}

Tanımlayıcı istatistik bulgularına göre katılımcıların GAB ön test ortalamaları 2.93 (SS=1.59, \%14.65) ve ÖAB ön test ortalamaları 0.24 (SS=.11, \%0.55) olarak belirlenmiştir. Voleybol dersi sonrası toplanan verilerde GAB ortalamasının 16.59 (SS= 2.47, \% 82.95) ve ÖAB ortalamasının 0.87 (SS=1.12, \% 4.35) 
olduğu tespit edilmiştir. Bulgular, katılımcıların yeterli alan bilgisi düzeyi için gerekli kriteri (\%70 ve üzeri doğru cevap) sağladıkları ancak ÖAB için gerekli değeri (3.0 ve üzeri) yakalayamadıklarını göstermektedir.

Tablo 1. Katılımcıların Genel ve Özelleşmiş Alan Bilgisi Ortalamaları

\begin{tabular}{lcccc}
\hline & \multicolumn{2}{c}{ Ön Test } & \multicolumn{2}{c}{ Son Test } \\
\cline { 2 - 5 } & $X^{-}$ & SS & $X^{-}$ & SS \\
\hline Genel alan bilgisi & 2.93 & 1.59 & 16.59 & 2.47 \\
\hline Özelleşmiş alan bilgisi & .24 & .11 & .87 & 1.12 \\
\hline
\end{tabular}

Bağımlı örneklem t-testi sonuçları tablo 2'de gösterilmektedir. Bulgulara göre katılımcıların GAB ön ve son testleri arasında anlamlı farklıık bulunmuştur $(t(28)=23.31, p<.05)$. Özelleşmiş alan bilgisi son test değerleri ön test değerlerine göre anlamlı düzeyde yükselmiştir ( $t(28)=4.19, p<.05)$.

Tablo 2. Bağımlı Örneklem T-Testi Tablosu

\begin{tabular}{lccccc}
\hline & $X^{-}$ & SS & $t$ & df & $p$ \\
\hline GAB ön ve son test & 13.66 & 3.15 & 23.31 & 28 & .00 \\
ÖAB ön ve son test & .87 & 1.12 & 4.19 & 28 & .00 \\
\hline
\end{tabular}

\section{Tartışma ve Sonuç}

Bu çalışmanın amacı voleybol dersini yeni tamamlamış beden eğitimi öğretmenliği bölümü öğrencilerinin voleybol alan bilgisi düzeyinin incelenmesidir. Katılımcıların 14 haftalık voleybol dersi sonrasında genel alan bilgisi ortalaması 16.59 (\% 82.95) olarak bulunmuştur. Bu değer, yapılan çalışmalara göre bilgi testlerinden başarılı olabilme kriterini (\%70 ve üzeri doğru cevap) sağlamıştır (Castelli \& Williams, 2007; South Carolina Department of Education [SDE], 2000). Benzer bulgular alan yazında görülmektedir. Devrilmez (2016) yaptığı çalışmada 10 haftalık badminton dersi sonrasında öğrencilerin GAB düzeyi beklendik seviyenin üzerine çıkmıştır. Çalışmamızda yer alan katılımcıların yarısından fazlasının $(\mathrm{N}=20)$ dersi almadan önce voleybol branşı ile ilgili antrenörlük ya da sporculuk deneyimine sahip olmalarına rağmen ön test bulguları oldukça düşük (\%14.65) bulunmuştur. Bu durum beden eğitimi ve spor öğretmenliği bölümü voleybol dersine kadar geçen öğretim sürecinin katılımcıların voleybol GAB'ne katkı sağlamadığını göstermektedir. Katılımcıların 14 haftalık GAB odaklı voleybol dersi ile istenen GAB düzeyine ulaşmış olmaları, uygulanan dersin GAB gelişimine katkı konusunda etkili olduğunu göstermektedir.

Çalışmamızdan elde edilen yeterli GAB düzeyi, alan yazındaki çalışmalarda farklıık göstermektedir (Capel \& Katene, 2000; Dervent vd., 2018; Ince \& Hunuk, 2013; Santiago, Disch, \& Morales, 2012). Beden eğitimi öğretmenlerinin sağlıkla ilgili fiziksel uygunluk alan bilgisi düzeyi incelenmiştir. 
Çalışmalar beden eğitimi öğretmenlerinin (İnce \& Hunuk, 2013) ve ilkokul öğretmenlerinin (Santigo vd., 2012) sağlıkla ilgili fiziksel uygunluk alan bilgisi düzeyini beklenen düzeyin altında bulmuştur. Beden eğitimi alanında ise spor ve fiziki etkinlikler derslerindeki alan bilgisi düzeyi incelenmiştir (Dervent vd., 2018; Devrilmez, 2016). Futbol dersini yeni tamamlayan beden eğitimi öğretmen adaylarının futbol GAB düzeyleri incelenmiştir. Katılımcılar 30 soruluk futbol bilgi testinde ortalama 16.07 (\%53.56) soruya doğru cevap vermiş olsalar da beklenen skora ulaşamamışlardır (Dervent vd., 2018).

Araştırmamızın ÖAB bulgularına göre beden eğitimi öğretmenliği bölümü öğrencilerinin son testler değerleri ön test değerlerine göre istatistiksel olarak anlamlı farklıık göstermiştir. Bununla birlikte, katılımcıların elde ettikleri son test ortalaması 0.87 ile derin ÖAB düzeyi (3.0 ve üzeri) için yeterli değildir. Düşük ÖAB düzeyi yakın zamanda yapılan çalışmalarda görülmektedir (Iserbyt \& Coolkens, 2018; He, Ward, Wang, \& Li, 2017; Ward vd., 2018). He ve arkadaşları (2017) 384 Çinli beden eğitimi öğretmeninin futbol ÖAB düzeylerini incelemiştir. Çalışmanın bulgularına göre öğretmenlerin çoğunluğu (\% 78.2) düşük ÖAB düzeyine sahiptirler.

Beden eğitimi öğretmen adaylarının, öğretmen yetiştiren kurumlardan mezun olmadan önce fiziksel aktivite ve spor dersleri için yeterli ve derin ÖAB'ne sahip olmaları beklenmektedir (Siedentop, 2002). Özellikle ÖAB düzeyi arttırılan öğretmenlerin PAB düzeylerinin artması (Kim; 2016; Kim vd., 2018; Sinelnikov vd., 2016), ÖAB'nin önemi de arttırmaktadır. Çalışmamızda yer alan beden eğitimi öğretmen adaylarının düşük ÖAB düzeyi nedeniyle gerçek okul beden eğitimi derslerinde voleybol öğretiminde zorlanmaları beklenebilir.

Sonuç olarak, araştırmamıza katılan beden eğitimi öğretmen adaylarının voleybol GAB düzeyleri istendik seviyededir. Bu seviye beden eğitimi öğretmen adaylarının voleybol branşında ne öğretileceğini ve nasıl performans gösterileceğini bildiklerini belirtmektedir. Katıımcıların GAB alt boyutundaki başarısı ne yazık ki ÖAB düzeyinde tespit edilememiştir. Düşük ÖAB'ne sahip olan beden eğitimi öğretmen adaylarının voleybol branşının nasıl öğretileceği konusunda yeterli olmadıklarını göstermektedir. Bu durumun okul beden eğitimi derslerinde voleybol öğrenen öğrencilerin öğrenme düzeyini de olumsuz etkilemesi beklenebilir. GAB odaklı bir ders sonrası öğretmen adaylarının GAB düzeyleri de anlamlı olarak artmıştır. Bu bulgu, öğretim programına ait içerik ve uygulama odağının öğrenme çıktılarına doğrudan etkisinin olduğunu göstermektedir. Dolayısıyla beden eğitimi öğretmen adaylarının öğretim kalitesini doğrudan etkileyen ÖAB de ancak ona odaklanan içerik ve uygulamalarla kazandırılabilir. Bu nedenle beden eğitimi ve spor öğretmenliği lisans programında yer alan fiziksel aktivite ve spor derslerinin uygulamada da ÖAB odaklı olarak öğretilmesi önerilmektedir.

\section{Kaynakça}

Aslan, N. (1979). Okullarda ve Kulüplerde Voleybol. Ankara Bilim Matbaası.

Ball, D.L., Thames, M.H., \& Phelps, G. (2008). Content knowledge for teaching: What makes it special? Journal of Teacher Education, 59(5), 389-408.

Capel, S., \& Katene, W. (2000). Secondary PGCE PE students' perceptions of their subject knowledge. European Physical Education Review, 6(1), 46-70.

Castelli D., Williams L. (2007). Health-related fitness and physical education teachers' content knowledge. Journal of Teaching in Physical Education, 26, 3-19.

Creswell, J. W. (2012). Educational research: Planning, conducting, and evaluating quantitative and qualitative research (4th ed.). Boston, MA: Pearson Education, Inc.

Dervent, F., Tsuda, E., Devrilmez, E., \& Ward, P. (2016). Content development coding assessment manual. Version2.1. Erişim adresi: https://u.osu.edu/ltpe/. 
Dervent, F., Ward, P., Devrilmez, E., \& Tsuda, E. (2018). Transfer of content development across practica

in physical education teacher education. Journal of Teaching in Physical Education, 37(4), 330-339.

Devrilmez E. (2016). Impact of badminton course designed for common and specialized content knowledge of prospective teachers. Yayımlanmamış Doktora Tezi. Orta doğu Teknik Üniversitesi. Sosyal Bilimler Enstitüsü.

Devrilmez, E., Dervent, F., \& Yoruç Çotuk., M. (2019). Validation of volleyball common content knowledge test. International Journal of Sport, Exercise \& Training Sciences, 5 (1), 31-39.

Grossman, P.L. (1990). The making of a teacher: Teacher knowledge and teacher education. Teachers College Press, Teachers College, Columbia University.

Hastie, P.A., \& Vlaisavljevic, N. (1999). The relationship between subject-matter expertise and accountability in instructional tasks. Journal of Teaching in Physical Education, 19(1), 22-33.

He, Y., Ward, P., Wang, X., \& Li, W. (2017). Chinese physical education teachers' specialized content knowledge of soccer. Research Quarterly for Exercise and Sport Supplement, 88, A4.

ince M.L. \& Hünük D. (2013). Experienced physical education teachers' health-related fitness knowledge level and knowledge internalization processes. Education and Science, 38 (168), 304-317.

Iserbyt, P., \& Coolkens, R. (2018). Content development as a function of content knowledge courses in preservice physical education teachers. Journal of Physical Education and Sport, 18(4), 2440-2446.

Iserbyt P., Ward P., Martens J. (2015). The Influence of content knowledge on teaching and learning in traditional and sport education contexts: an exploratory study. Physical Education and Sport Pedagogy. 21(5), 539-556.

Kim, I. (2016). Exploring changes to a teacher's teaching practices and student learning through a volleyball content knowledge workshop. European Physical Education Review, 22(2), 225-242

Kim, I., Ward, P., Sinelnikov, O., Ko, B., Iserbyt, P., Li, W., \& Curtner-Smith, M. (2018). The influence of content knowledge on pedagogical content knowledge: An evidence-based practice for physical education. Journal of Teaching in Physical Education, 37 (2), 133-143.

Santiago, J.A., Disch, J.G., \& Morales, J. (2012). Elementary physical education teachers' content knowledge of physical activity and health-related fitness. Physical Educator, 69 (4), 395-412.

Shulman, L.S. (1986). Those who understand: Knowledge growth in teaching. Educational researcher, 15(2), 4-14.

Shulman, L.S. (1987). Knowledge and teaching: Foundations of the new reform. Harvard Educational Review, 57(1), 1-23.

Siedentop, D. (2002). Sport education: A retrospective. Journal of Teaching in Physical Education, 21(4), 409-418.

Sinelnikov, O.A., Kim, I., Ward, P., Curtner-Smith, M., \&Li, W. (2016). Changing beginning teachers' content knowledge and its effects on student learning. Physical Education and Sport Pedagogy, 21(4), 425-440.

South Carolina Department of Education. (2000). South Carolina physical education curriculum standards. Columbia, SC: South Carolina Department of Education.

Spor Genel Müdürlüğü (2018). http://sgm.gsb.gov.tr/Sayfalar/175/105/Istatistikler. Erişim tarihi: 2 Şubat 2019.

Tsuda, E., Devrilmez, E., Dervent, F., \& Ward, P. (2017). Differences in content knowledge between those who learned performing and teaching. Research Quarterly for Exercise and Sport Supplement, 88, A4.

Van der Mars, H. (1989). Observer reliability: Issues and procedures. Analyzing Physical Education and Sport Instruction, 2, 53-80. 
Ward, P. (2009). "Content Matters: Knowledge that Alters Teaching." In Historic Traditions and Future Directions of Research on Teaching and Teacher Education in Physical Education, edited by L. Housner, M. Metzler, P. Schempp, and T. Templin, 345 -356. Morgantown, WV: Fitness Information Technology.

Ward, P., \& Ayvazo, S. (2016). Pedagogical content knowledge: Conceptions and findings in physical education. Journal of Teaching in Physical Education, 35, 194-207.

Ward, P., Dervent, F., Lee, Y.S., Ko, B., Kim, I., \& Tao, W. (2017). Using content maps to measure content development in physical education: Validation and application. Journal of Teaching in Physical Education, 36, 20-31. doi:10.1123/jtpe.2016-0059.

Ward, P., Kim, I., Ko, B., \& Li, W. (2015). Effects of improving teachers' content knowledge on teaching and student learning in physical education. Research Quarterly for Exercise and Sport, 86 (2), 130-139.

Ward, P., Tsuda, E., Dervent, F., \& Devrilmez, E. (2018). Differences in the content knowledge of those taught to teach and those taught to play. Journal of Teaching in Physical Education, 37(1), 59-68.

Yerlisu, T., \& Çelenk, B. (2008). Liglerde görev yapan voleybol antrenörlerinin iş doyum düzeylerinin değerlendirilmesi. Spormetre Beden Eğitimi ve Spor Bilimleri Dergisi, 6(2), 87-93.

Yüksek Öğretim Kurumu (YÖK) (2018). Erişim adresi: https:/ /www.yok.gov.tr/Documents/ Kurumsal/eğitim_öğretim_dairesi/Yeni Öğretmen Yetiştirme- Lisans Programları/ Beden_Eğitimi_ve_Spor_Öğretmenliği_Lisans_Programı.pdf.

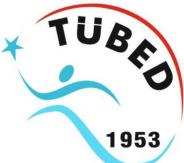

All rights reserved by Turkish Association of Physical Education Teachers. Tüm hakları Türkiye Beden Eğitimi Öğretmenleri Derneği'ne aittir. 